\title{
On the Distributive and Non-Distributive Interpretation in Japanese
}

\author{
Kenji Yokota \\ College of Industrial Technology, Nihon University, Chiba, Japan \\ Email: yokota.kenji@nihon-u.ac.jp
}

Received 7 August 2014; revised 2 September 2014; accepted 9 September 2014

Copyright (C 2014 by author and Scientific Research Publishing Inc.

This work is licensed under the Creative Commons Attribution International License (CC BY).

http://creativecommons.org/licenses/by/4.0/

(c) (i) Open Access

\begin{abstract}
Through an analysis of two different types of floating numeral quantifier (FNQ) constructions in Japanese, the present paper investigates the distributive and non-distributive interpretation in Japanese. Discussion of the interpretative issues related to ambiguity and intonation has indicated that FNQs are potentially ambiguous, offering both distributive and non-distributive readings.
\end{abstract}

\section{Keywords}

\section{Distributive, Non-Distributive, Floating Numeral Quantifier, Japanese}

\section{Introduction}

The purpose of this paper is to investigate the distributive and non-distributive interpretation in Japanese. This fundamental issue is one of the major concerns in Japanese linguistics. The meaning distinction has been sparsely discussed in the literature, but has rarely been examined in detail. This is presumably because the differentiation between distributive and non-distributive interpretations is to be accounted for in terms of structure, meaning, and context. To elucidate some aspects of the interpretative properties, the present study addresses floating numeral quantifier (FNQ) constructions in Japanese, which have long been analyzed as purely syntactic phenomena. ${ }^{1}$ We instead argue that these constructions are sensitive to discourse relations (e.g., informationstructure and intonation). Of much importance is that non-distributive readings in fact emerge under certain conditions. It is shown that existing research errs in assuming that FNQs in Japanese can only generate distributive readings, and that this error arises due to the incorrect treatment of non-syntactic aspects of these constructions.

\footnotetext{
${ }^{1}$ The term float does not have a precise, self-evident definition. Essentially, we will use it as a convenient label (or a figurative expression) for the FNQ phenomenon, partly because it is widespread in the literature.
} 


\section{Availability of Non-Distributive Interpretations}

The basic assumption of importance to the present discussion is as follows: FNQs in Japanese are potentially ambiguous, yielding both distributive and non-distributive readings (see Yokota 2013 for discussion). By way of illustration, let us look at (1) as a case in point. ${ }^{2}$ In Nakanishi (2004, 2007, 2008), the presence of a phonological boundary is briefly discussed as influencing the interpretation of an FNQ sentence. According to Nakanishi, sentence (1) seems to be ambiguous because it offers both distributive and collective (non-distributive in our terms) readings without a boundary; however, it only allows for a distributive reading with a boundary. (In the examples below, a phonological boundary that accompanies a long pause is indicated by "//". We also assume that the verb is read without any prosodic addition or particular additional intonation contour, such as an emphasis or focus).

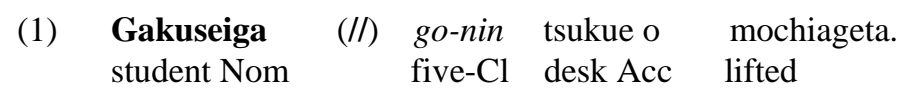

(i) "Five (of the) students lifted a desk (individually)" [Distributive].

(ii) "Five students lifted a desk (together)" [Non-distributive] (cf. Nakanishi, 2007, 2008).

When determining sentence meaning, to avoid the potential ambiguity and ensuing complications that reside in the FNQ sentence, Nakanishi focuses on a case wherein a certain element (e.g., kinoo "yesterday") intervenes between an FNQ and its host nounto make the FNQ sentence produce a distributive meaning, as in (ii). However, as Nakanishi admits, we must inevitably question the implications of the data presented in (1) with regard to the theory of FNQ constructions in Japanese. Unlike relevant syntactic analyses, the current study posits that the role of information-structure and prosody cannot be ignored in syntactic research.

An assumption that has not been called into question is that an FNQ is a distributive operator (Kobuchi, 2003, 2007; Nakanishi, 2004, 2007, 2008). In terms of semantics, for many researchers the denotation of an FNQ is never interpreted as an established set. They claim that due to the lack of status as an established set, the FNQ cannot have a non-distributive reading and each instantiated entity must be individually involved in the event or action to produce a necessarily distributive reading as provided in ((1) (i)). However, the issue with FNQ semantics has not yet been sufficiently explained. It should be noted that appropriate intonation (in the right context) can even make the non-distributive FNQ interpretation the most natural one, as seen in ((1) (ii)). Evidently, the difficult issue here is identifying a non-distributive reading, but there is indeed a natural reading of non-distributive FNQs.

Let us take a look at another case in point. Sentence ((2) a) does not allow for a distributive reading without a pause (or phonological boundary), as in ((2) b). However, this reading becomes acceptable with a pause that is immediately inserted after the FNQ, as in ((2) b) (Miyagawa \& Arikawa, 2007: pp. 661-662).

\begin{tabular}{|c|c|c|c|c|}
\hline $\begin{array}{l}\text { a. Gakusei ga } \\
\text { student Nom }\end{array}$ & $\begin{array}{l}\text { kinoo } \\
\text { yesterday }\end{array}$ & $\begin{array}{l}\text { san-nin } \\
\text { three-Cl }\end{array}$ & $\begin{array}{l}\text { Peter o } \\
\text { Peter Acc }\end{array}$ & $\begin{array}{l}\text { koroshita. } \\
\text { killed }\end{array}$ \\
\hline “Three students & as a group) & led Peter ye & day” (Naka & hi, 2007: p. 53 \\
\hline $\begin{array}{l}\text { b. Gakusei ga } \\
\text { student Nom }\end{array}$ & $\begin{array}{l}\text { kinoo } \\
\text { yesterday }\end{array}$ & $\begin{array}{l}\text { san-nin } \\
\text { three-Cl }\end{array}$ & $\begin{array}{l}\text { Peter o } \\
\text { PeterAcc }\end{array}$ & $\begin{array}{l}\text { koroshita. } \\
\text { killed }\end{array}$ \\
\hline
\end{tabular}

The above example demonstrates that even though a sentence is deemed ungrammatical, it can still be used in certain circumstances. Note that, as indicated in the English translation in ((2) b), the contribution of the FNQ meaning is not distributive. In other words, the verb korosu "kill" used in (2) ensures that the sentence is not distributive in terms of individuals or events (see Section 3.1 for the definition of distributivity).

Examples (1) and (2) strongly indicate that we may not be able to think of FNQs as distributive operators. ${ }^{3}$ If this is the case, the previous analyses that treated FNQs as simply distributive would need an additional mechanism to account for the presence of non-distributive readings (e.g., (1) (ii) and (2) b)). Contrary to existing studies, we assume that FNQ interpretation follows the assumption that a particular intonation and interpretation

\footnotetext{
${ }^{2}$ In the examples below, the quantifier has been italicized and its host noun boldfaced. The abbreviation $\mathrm{Cl}$ stands for classifier. This paper focuses on subject-oriented (or subject-related) FNQ sentences in Japanese. Unless indicated, all examples cited in the study revolve around Japanese subject-oriented FNQ sentences, wherein the host noun (or the subject) bears the nominative marker -ga; the nominative marker is generally assumed to signal the separation of the FNQ from the host noun.
} 
are distinctly assigned to FNQ sentences (even in silent reading) either as NP-related FNQs (in which the subject NP and its associate FNQ form a single intonational phrasing) or as VP-related FNQs (in which the subject NP and its associate FNQ form multiple intonational phrasings).

The issue of the distributive and non-distributive interpretation illustrated so far suggests that a reconsideration of past data on distributive or non-distributive readings is advisable. The fundamental question to be answered is why such sentences are ambiguous, offering both distributive reading and non-distributive readings. ${ }^{4}$ In an attempt to answer this question, we present evidence in support of the claim that FNQs are ambiguous between NP-related FNQs and VP-related FNQs, and preference is a matter of degree. In sentence interpretation, the FNQ is associated with either the subject NP or the verb, especially when contextual or prosodic information is not readily available. We suggest that both context and prosody, in addition to syntax and semantics, contribute to the disambiguation of an FNQ (whether NP-related or VP-related) and overall acceptability of the sentence, which proves to be tenable in the following two sections.

\section{Ambiguous Interpretation}

To describe the differences between VP-related FNQs (i.e., event quantifiers) and NP-related ones (i.e., individual/object quantifiers), it is necessary to re-examine Japanese FNQs, which have been widely analyzed as adverbs, in terms of interpretation and intonation.FNQ interpretation is the result of distinctive levels of interrelated phenomena, both syntactic and discourse-pragmatic. To clarify factors affecting FNQ interpretation, we will limit our discussion to the ambiguity between distributive and non-distributive and between partitive and non-partitive interpretations.

\subsection{Distributivity and Non-Distributivity}

In general, different readings involve different truth conditions in accordance with information-structure (cf. Jackendoff, 1972; Kadmon, 2001; Dalrymple \& Nikolaeva, 2010). We will get a handle on influencing factors and how these factors are involved in establishing an appropriate link among the host NP, the FNQ, and the verbal predicate in an FNQ sentence. Observations made in this study are confined to FNQs that are separated from (but consequently associated with) their subjects. For the sake of our analysis, we provide a description of distributives and non-distributives in (3), adopted from Stirling (1985: p. 17) (emphasis added). As indicated, distributivity entails a multiplicity of temporal entities or events, which will be particularly relevant to the following discussion.

(3) Generalization over distributive and non-distributive readings (Stirling, 1985: p. 17).

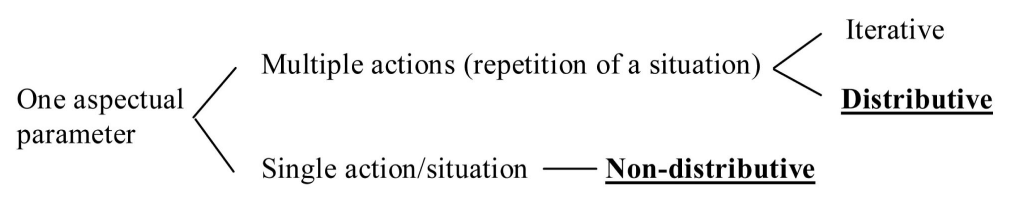

The terms distributive and non-distributive are used throughout our discussion in the sense of Kitagawa and Kuroda (1992). Note that their usage of distributivity in relation to action or situation in fact seems somewhat different from the one commonly used in the literature of semantics (cf. Landman, 1989a, b; Kobuchi, 2003, 2007; Nakanishi, 2004, 2007, 2008).

It is, however, not entirely clear whether the distributivity in question can be defined only in terms of agent (rather than event) to account for all the FNQ facts in Japanese (e.g., (1) and (2)). One important aspect concerning distributivity and its construal is that there are cases wherein distributivity appears to involve distribution of events (single or multiple), rather than agents (see also section 3.2). Although this type of distributive reading is contrasted with a non-distributive (or collective) reading in the literature, regardless of the definition

\footnotetext{
${ }^{3}$ For instance, Kobuchi (2003) and Nakanishi (2004) insist that this non-distributive reading can still be explained according to their theory by modifying the cover reading. Whether this is the correct direction to pursue depends on what the notion of distributivity is and whether the FNQ is indeed a distributive operator in the sentence.

${ }^{4}$ In semantic terms, when the denotation as a set (group) is highlighted, the FNQ presumably has a non-distributive reading. By contrast, when the individuality in the denotation as a set of individuals is highlighted, the FNQ has a distributive reading.
} 
(agents or events) chosen, the distributive reading must be identical within the analysis of FNQ constructions. However, this is not established by examples (1) and (2) in the previous section. Therefore, it seems reasonable to continue using Kitagawa and Kuroda's definition of distributive readings in relation to events rather than agents. $^{5}$

Based on the distinction between distributivity and non-distributivity shown in (3), we will consider the correlation between the distributive or non-distributive contrasts in conjunction with partitive or non-partitive denotations. As will become clear below, identifying the ambiguity of these four related readings clarifies what has been lacking in previous studies and provides an empirical basis for reaching a better understanding of FNQ interpretation.

In light of examples (1) and (2) in Section 2, the phenomenon referred to as the distributive or non-distributive distinction appears to be relevant to a more general discourse-pragmatic system. In principle, an FNQ expression gives rise to a set of possible interpretations; hence, resulting in ambiguity. It is then likely that a hearer is able to identify one optimal interpretation for the FNQ expression in relation to the context.

It has been generally assumed that a quantification that ranges over the extensions of a noun is called distributive (see Kobuchi, 2003, 2007; Nakanishi, 2004, 2007, 2008). However, Kitagawa and Kuroda (1992) define distributive reading in terms of reference to events. ${ }^{6}$ Below we present some data from their work. In their theory, a distributive reading necessarily implies the occurrence of multiple events, while a non-distributive reading implies the occurrence of a single event. Kitagawa and Kuroda’s (1992: pp. 68-69) examples used to illustrate the contrast are as follows:

\section{(4) Distributive}
a. Kono isshuukan no aidani shuujin ga san-nin nigedashita. this one week Gen during prisoner Nom three-Cl escaped
"There have been three jailbreaks this week".

\section{Non-distributive}
b. Sonotoki totsuzen shuujinga san-nin abaredashita. then suddenly prisoner Nom three-Cl started.to.act.violently "Then, a group of three prisoners suddenly started to act violently".

According to Kitagawa and Kuroda's description of distributivity, ((4) a) is distributive and ((4) b) is non-distributive because in the interpretation of ((4) b) there is only a single event of violent behavior by three prisoners. More precisely, ((4) a) is distributive (each member of the set of prisoners is the agent of an event of escaping) and ((4) b) is non-distributive (all the prisoners act as a collective agent behind a single event of starting to act violently). However, as Ishii (1999) points out, ((4) b) has a distributive reading in addition to its non-distributive reading. That is, ((4) b) can be interpreted as distributive since started to act violently applies to each prisoner, even if the actions of the three prisoners occurred suddenly and at the same time. This observation seems valid because the quantification in question can range over the extensions of a noun (Yokota, 2013). Therefore, more careful attention is needed to provide a better account of FNQ interpretation.

\subsection{Partitivity and Non-Partitivity}

It seems necessary to consider the partitive and non-partitive interpretations appearing in the FNQ construction. Kitagawa and Kuroda (1992) claim that a contrast in meaning sometimes shows up between "local” (as in ((6) a) and ((7) a) below) and "non-local" (as in ((6) b) and ((7) b) below) quantifier floats.

(5) Local quantifier float permits either partitive or non-partitive interpretation, whereas non-local quantifier float permits only partitive interpretation (Kitagawa \& Kuroda, 1992: p. 70).

With their descriptive generalization in (5), Kitagawa and Kuroda contend that this contrast is observed only when the floating quantifier is intended to be non-distributive, as stated in (6) (Kitagawa \& Kuroda, 1992: p. 70).

\footnotetext{
${ }^{5}$ We also use the term "non-distributive" when citing examples and arguments by previous authors who used this expression.

${ }^{6}$ Kitagawa and Kuroda's (1992) aim was not to present a complete theory of Japanese FNQs; nevertheless, the present study draws upon their work because it offers important empirical insights in considering the interpretation of FNQ sentences (see Nakanishi, 2007,2008 for criticism).
} 


\section{(6) Non-distributive}
a. Mukoo kara arui-te-kita
there from came.on.foot
gakusei ga
$\begin{array}{ll}\text { huta-ri } & \text { boku no } \\ \text { two-Cl } & \text { I Gen }\end{array}$
me no mae de
keisatsu ni
taihos-are-ta.
student Nom two-Cl I Gen
in.front.of
police by
arrest-Pass-Past
"Two students/two of the students walking toward me were arrested by the police".
b. Mukookara arui-te-kita gakusei ga boku no me no mae de keisatsuni
there from came.on.foot student Nom I Gen in.front.of police by
hutari taihos-are-ta.
two-Cl arrest-Pass-Past
"Two of the students walking toward me were arrested by the police".

Kitagawa and Kuroda observe that when an FNQ prompts a distributive reading, the contrast does not appear, as the English translations indicate. However, as observed in ((4) b), sentence ((6) b) also permits a partitive (and distributive) construal rather easily for the same reason; this fact should not be overlooked.

Let us now turn to a distributive construal (taken from Kitagawa \& Kuroda 1992: p. 69).

\section{(7) Distributive}
a. Senshuu, soshite konshuu to
last week and this week
sooko ni nokotteita
warehouse in remaining
$\begin{array}{ll}\text { kuruma ga } & \text { ni-dai } \\ \text { car Nom } & \text { two-Cl }\end{array}$
doroboo ni nusum-are-ta.
thief by steal-Pass-Past
"With the break-ins that took place last week and this week, two cars/two of the cars left in the warehouse were stolen”.
b. Senshuu, soshite konshuu to sooko ni nokotteita kuruma ga dorobooni
last week and this week warehouse in remaining car Nom thief by
ni-dai nusum-are-ta.
two-Cl steal-Pass-Past
"With the break-ins that took place last week and this week, two cars/two of the cars left in the warehouse were stolen”.

According to Kitagawa and Kuroda, both ((7) a) with local quantifier float and ((7) b) with non-local quantifier float are deemed ambiguous with respect to partitive and non-partitive interpretations, as the corresponding translations indicate. However, Kitagawa and Kuroda's observation is not correct concerning ((7) b). The nonpartitive interpretation given in the translation (i.e., two (and only two) cars left in the warehouse were stolen) is not easily obtained. In addition, there are certain cases wherein a non-local FNQ yields only a non-partitive distributive reading, as shown in the following elaborate example (taken from Takami,1998: p. 91).
A: Kono shinkan zasshi ure-teimasu-ka. this new magazine selling is-Q
"Is this new magazine selling well?"
B: Ee, kesa mo gakusei-san ga sore o go-nin kat-teiki-mashita-yo yes, this morning also student Nom it Acc five-Cl buy go-Past "Yes, five students have bought it this morning".

As Ishii (1998) claims, utterance ((8) B) has only a distributive (or cumulative) reading. In this discourse, according to Ishii, there is no predefined set of students, and hence, go-nin "five-Cl" does prompt a partitive reading. We assume, following Yokota (2013: Chapter 4), that an NP-related FNQ can function as a maximality operator (iota, in formal semantic terms), which entails that the FNQ takes the maximal member of the given set (see, e.g., Giannakidou \& Cheng 2006 for description), which is interpreted as non-partitive.

From ((7) b) and ((8) B) above, we can deduce that a partitive or non-partitive reading is not guaranteed by an FNQ construction. In other words, the placement of the FNQ after the case particle -ga "Nom" does not guarantee the possibility of a partitive interpretation. A partitive interpretation is often prosodically signaled with marked intonation including pausing (Kitagawa \& Kuroda, 1992; Ishii, 1998). Undoubtedly, inferences about scenarios or contexts have affected the interpretation of FNQs as partitive or non-partitive in (8). This means 
that the interpretation of FNQs is more discourse related than previous studies may have supposed.

Given the considerations so far, it is not clear how Kitagawa and Kuroda address the difference in interpretation with regard to partitive vs. non-partitive readings in ((7) b) and ((8) B) by relying on their generalization in (5). This generalization incorrectly predicts that a non-local quantifier float with a distributive reading permits either a partitive or a non-partitive interpretation. We must admit that (5) is not an effective hypothesis to illustrate all the interpretative facts involving FNQs, local or non-local.

To address these points, we suggest that in principle (at least) four readings are possible in local or non-local FNQ constructions, as Table 1 summarizes. ${ }^{7}$ The binary features [+/-part(itive)] and [+/-dist (ributive)] can exhaustively define the FNQ constructions. Note that in an FNQ sentence semantics generates both of the possible readings of quantifiers and preference is determined by non-syntactic factors such as information-structure and prosody.

As shown in Table 1, there are in principle at least four possible interpretations regarding the partitivity and distributivity assigned to local and non-local FNQs. What we should determine is which successful derivation leads to the intended reading. It is noteworthy that non-distributive examples such as ((1) (ii)), (2), ((4) b), and ((6) a, b), are considered problematic by previous studies, which commonly assume that the FNQ obligatorily functions as a verbal modifier (i.e., a quantifier over events) and systematically yields distributivity as the default reading (see Kobuchi, 2003, 2007; Nakanishi, 2004, 2007, 2008, among others). These assumptions need to be modified before they can be incorporated.

Whether we define the meaning of distributive reading in terms of reference to individual objects (agents) or events (situations), observations by researchers including Kitagawa and Kuroda (1992), Ishii (1998, 1999), Takami (1998) are correct and still deserve careful attention. It is important to note that both (non-) distributivity and (non-) partitivity play an important role in the felicity of FNQ sentences, whether they are local or non-local.

As can be seen from Table 1, FNQ constructions do not necessarily guarantee a distributive reading in terms of reference to agents (contrary to what previous studies have concluded). This is presumably because there are two types of FNQs in Japanese. That is, FNQs are primarily associated with either the subject NP or the verb. Hence, it is not easy to characterize FNQs simply in terms of agents.

\section{Intonation}

As briefly discussed in Section 2, the interpretation of FNQ sentences is well described in prosodic terms, and a theory based on prosody should explicitly account for FNQ interpretation. The key to understanding FNQ interpretation is the awareness of distinct intonational patterns between VP-related and NP-related FNQs. ${ }^{8}$ Ourmajor concern here is what happens when two potential accent phrases (APs) (for example, the FNQ and its host noun) combine. In general, when the two phrases form a syntactic and semantic unit, the combination of a sequence as a single AP (and intonational phrase (IP) as well) is possible, as long as neither component is emphasized (cf. Pierrehumbert \& Beckman, 1988; Kubozono, 1993).

\subsection{Prosodic Effects on FNQ Interpretation}

We are assuming that in nearly all cases involving an FNQ, the sentences can be considered ambiguous with

Table 1. Distribution of interpretations of Japanese FNQs.

\begin{tabular}{ccccc}
\hline & +part, +dist & -part, +dist & +part, -dist & -part, -dist \\
\hline Local FNQ & (1)(i), (4) a, (7) a & (1)(i), (7) a & (4) b, (6)a & (1)(ii), (6) a \\
Non-local FNQ & (7) b & (7)b, (8) B & (6)b & (2)b \\
\hline
\end{tabular}

\footnotetext{
${ }^{7}$ Although Kitagawa and Kuroda (1992) do not discuss this, examples such (1) and (2) would fill the empty slots, i.e., non-local FNQs with [-part, -dist] (non-partitive non-distributive reading).

${ }^{8}$ Intonational variation has been much studied in its role in the interpretation of numerous discourse phenomena. We assume that FNQs are differently interpreted depending upon whether they are prominent in varying contexts. Different categories of information status, such as theme or rheme distinctions, given or new status, and contrast are believed to be intonationally markable (cf. Jackendoff, 1972; Steedman, $2000 \mathrm{a}, \mathrm{b})$. There seem to be certain cases wherein prosody provides important indications of informational structure, and information structure roles are aligned to phrase structure.
} 
distributive and non-distributive readings both possible. ${ }^{9}$ We will examine meaningful ways in which information-structure of utterances involving Japanese FNQs is influenced by intonation. We describe the two prosodic structures that could distinguish VP-related FNQs from NP-related FNQs. For illustration, we consider an example (9). In general, the listener tends to group lexical materials into a prosodic package and she or he determines the start and end of each package on the basis of prosodic information, especially relevant F0 (fundamental frequency) register scaling (e.g., down step or pitch register reset), wherein the pitch range is sensitive to information structure (e.g., the enlarged pitch range for new information and the compressed one for given information) (cf. Fodor, 2002; Kitagwa \& Fodor, 2006; Féry \& Ishihara, 2009) ${ }^{10}$ In addition, as Pierrehumbert and Beckman (1988: pp. 7, 19-20, 99-101) point out, focus creates a phonological boundary before the focused material and at the same time destroys the ones following it. When pronounced, a pitch reset is observed on the FNQ san-nin "three-Cl" in ((9) a), while a downstep (rather than a pitch reset) is observed on the FNQ in ((9) b).

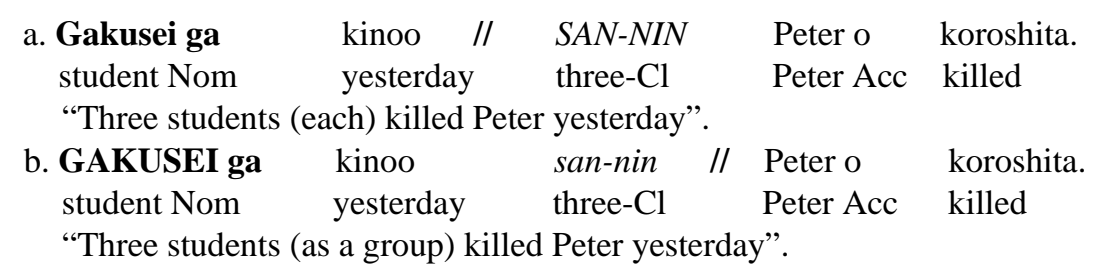

In previous studies, Japanese FNQ constructions have been presented in written form and interpreted without any context. This approach would be problematic for the present study because the information structure of a sentence is affected by context, prosody, or both. Such a reading test with written stimuli is necessarily based on self-paced reading, which often only reflects readers' default prosody (Kiaer, 2005: p. 7). In the reading test, marked (or non-default) prosody cannot be immediately incorporated in the general theory of FNQ constructions.

To resolve this problem, we should first examine the data on FNQ constructions provided in the existing literature. We take the position that not a few FNQ examples deemed ungrammatical by researchers are in fact grammatical, and contrary judgments are probably due to a failure to assign the appropriate prosodic contour (Yokota, 2013). This may be a type of clash between the prosody that is required for an NP-related FNQ interpretation and the default intonation (which yields a VP-related FNQ reading) that a reader or listener may automatically assign.

Restricting our attention to cases involving a subject-oriented FNQ, we suggest that quantifier float potentially gives rise to ambiguity between distributive and non-distributive readings. To clarify, we consider another case involving non-distributive readings, as in (10). Kobuchi (2003, 2007) and Nakanishi (2004, 2007, 2008) point out that a sentence like (10) is ungrammatical. The judgment here is Nakanishi's, based on the assumption that a distributive reading is not available for this FNQ construction. According to her theory, despite a pragmatic need for a non-distributive reading, only a distributive reading is assigned to the sentence as the FNQ is located within the VP.

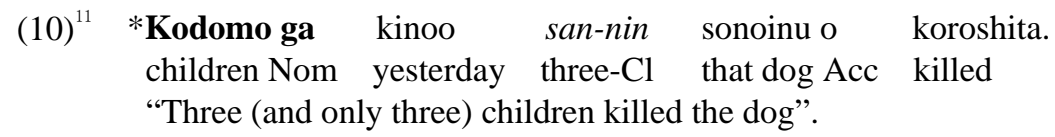

The grammatical assessment of existing research seems problematic mainly because the target sentences are provided without any particular context. As we saw in ((9) b), sentence (10) becomes felicitous as well, even if

\footnotetext{
${ }^{9}$ As Kobuchi $(2003,2007)$ notices, the distinction between these two interpretations can be sensed in silent reading only when we succeed in mentally associating them with distinct prosodic patterns as in (i) and (ii), wherein “//” indicates pauses. Note that both are possible prosodic phrasings of an FNQ sentence: (i) [[Gakuseiga san-nin//]kita]. (ii) [Gakuseiga]//[san-ninkita]. This situation, however, is not as simple as Kobuchi supposes (see Yokota 2013 for discussion).

${ }^{10}$ It is generally held that F0 of speech sounds tends to decrease over the course of an utterance, and the literature has identified two major prosodic events, other than downstep, as the main causes of this tendency. One is a phonetic effect of "declination"-F0 gradually declines from the beginning of the utterance as a function of time. The other is a phonetic rule of "final lowering," which significantly lowers F0 at the end of each declarative utterance (cf. Poser, 1984; Pierrehumbert \& Beckman, 1988; Kubozono, 1993; Ishihara, 2011). The point of the current discussion is that there is a prosodic distinction depending on the presence or absence of a sharp pitch reset on the FNQ.

${ }^{11}$ Kobuchi (2003, 2007) makes use of “*” (ungrammatical), rather than “\#” (infelicitous) in her account. Kobuchi claims that this reflects the intuition of several native speakers that many of these examples sound ungrammatical and cannot be improved by context. However, this claim seems too strong (see (1) and (2) in Section 2).
} 
it is initially considered in an impossible "out-of-the-blue" context.

For instance, one can easily imagine a possible context in which sentence (10) is uttered during the discussion of an awful incident, in which that dog has been killed by someone. Here, sonoinuo koroshita "killed that dog" is regarded as topic rather than focus. What is emphasized here is the subject noun, kodomo "children". In this particular situation, the FNQ san-nin "three-Cl" is the non-focus element, which is defined as neither topic nor focus (see Dalrymple \& Nikolaeva, 2010 and references therein for discussions of information-structure roles). Miyagawa and Arikawa (2007: pp. 661-662, footnote 9) note that acceptability improves if a pause is inserted immediately after the FNQ. This is the assessment of informants when sentences are auditorily presented with controlled prosodic properties. Importantly, the FNQ in (10) can be phrased (non-locally) together with the subject, giving rise to a single downtrend intonation contour (see ((11) a) below).

\subsection{Improvement of Acceptability by Intonation}

The prosodic account developed in the current study can be viewed as an extension of the claim made in Miyagawa and Arikawa (2007) that prosody plays a crucial role in interpreting FNQ constructions in Japanese. It seems plausible that the strategy used by the speaker to avoid infelicitous readings was to form a single downtrend IP composed of the FNQ and its host noun within the same NP. This single phrasing is characterized by the accompaniment of lowered F0-peaks (i.e., downstep), rather than a sharp F0-riseon the pitch contour (i.e., pitch resetting).

Provided with contextual information, the interpretation and acceptability of sentence (10) changes, as does the prosodic pattern we can assign to it. For clarification, we further consider ((11) a). (Relevant intonational units are shown in square brackets to facilitate exposition.)

$$
\begin{aligned}
& \text { a. [Kodomo ga kinoo san-nin] // sonoinu o koroshita } \\
& \text { children Nom yesterday three-Cl that dog Acc killed } \\
& \text { "Three (and only three) children killed the dog" (cf. Miyagawa \& Arikawa, 2007). } \\
& \text { b. *Kodomo ga kinoo // [san-nin sonoinu o koroshita] } \\
& \text { children Nom yesterday three-Cl that dog Acc killed } \\
& \text { “Three (and only three) children killed the dog” (cf. Nakanishi, 2004; Kobuchi, 2006). }
\end{aligned}
$$

The FNQ and its associate NP in ((11) a) do not form a separate prosodic phrase. By contrast, in ((11) b) the quantifier, prosodically separated from the host NP, resides within the VP's intonational domain, resulting in an infelicitous reading for an NP-related (or non-distributive) FNQ. In this case, a VP-related (or distributive) reading is not available either, because of the semantic incompatibility ascribed to the meaning of the once only predicate korosu "kill". Hence, we must observe that unlike example ((11) b), the quantifier is computed within the NP rather than the VP, which is in fact the optimal interpretation available for ((11) a).

In the absence of further context and intonational cues, it stands to reason that different readings as observed in ((11) a) and ((11) b) arise simply as the result of a difference between the lexical content of the sentences and their respective contexts. There appears no structurally based, mechanical way in which correct interpretations are derived successfully, although different readings involve different truth conditions. We should note that the finding of the speakers' judgment concerning ((11) b) indicates that the VP-related FNQ reading is less natural because it would require heavier contextual framing to be felicitous. As exemplified in ((11) a), it is highly probable that the NP-related reading (rather than the VP-related one) is the preferred option under a given condition. However, previous studies do not discuss in detail the role of context in processing FNQ sentences like (10), nor do they answer the question as to whether or how an FNQ becomes the preferred structure and meaning in an otherwise potentially ambiguous structure.

\section{Conclusions}

Through an analysis of two different (NP-related and VP-related) types of FNQ constructions in Japanese, we e have provided a basis for the distributive and non-distributive interpretation. Discussion of the interpretative issues related to ambiguity and intonation has indicated that FNQs are ambiguous, offering both distributive and non-distributive readings. We have pointed out that existing theories do not seriously take non-syntactic factors into account and likewise fail to cover a range of FNQ aspects, in particular, non-distributive readings. Such apparently marked readings of FNQ constructions are shown to be closely associated with NP-related FNQ struc- 
ture, a matter on which little research has been conducted.

In this paper, Japanese FNQ sentences, commonly analyzed in terms of syntax, are re-examined in the light of growing awareness of the role played by prosody in language (cf. Fodor, 1995, 2002; Deguchi \& Kitagawa, 2002; Kitagawa \& Fodor, 2006). ${ }^{12}$ Syntactic structure, as Kitagawa and Fodor (2006: p. 340) argue, certainly influences prosodic structure, and speakers and listeners often use prosodic differences to disambiguate utterances of different syntactic structures. Taking into account that it is rare to encounter sentences without any context, we have examined how prosodic information interacts with a salient context in determining FNQ placement and interpretation. This study has the advantage of offering a way to handle the distributive and non-distributive interpretation in Japanese.

\section{References}

Dalrymple, M., \&Nikolaeva, I. (2010). Objects and Information Structure. Cambridge: Cambridge University Press.

Deguchi, M., \& Kitagawa Y. (2002). Prosody and Wh-Questions. In M. Hirotani (Ed.), Proceedings of the North East Linguistics Society (pp. 73-92).

Féry, C., \& Ishihara, S. (2009). How Focus and Givenness Shape Prosody. In M. Zimmermann, \& C. Féry (Eds.), Information Structure (pp. 36-63). Oxford: Oxford University Press.

Fodor, J. D. (1995). Comprehending Sentence Structure. In D. N. Osherson, L. R. Gleitman, \& M. Liberman (Eds.), An Invitation to Cognitive Science - Language (Vol. 1, pp. 209-246). Cambridge, MA: MIT Press.

Giannakidou, A., \& Cheng, L. L.-S. (2006). (In) definiteness, Polarity, and the Role of Wh-Morphology in Free Choice. Journal of Semantics, 23, 135-183. http://dx.doi.org/10.1093/jos/ffl001

Ishihara, S. (2011). Japanese Focus Revisited: Freeing Focus From Prosodic Phrasing. Lingua, 121, 1870-1889. http://dx.doi.org/10.1016/j.lingua.2011.06.008

Ishii, Y. (1998). Floating Quantifiers in Japanese: NP-Quantifiers, VP-Quantifiers, or Both? Researching and Verifying an Advanced Theory of Human Language, 2, 149-171.

Ishii, Y. (1999). A Note on Floating Quantifiers in Japanese. In M. Muraki, \& E. Iwamoto (Eds.), Linguistics: In Search of the Human Mind-A Festschrift for Kazuko Inoue (pp. 236-267). Tokyo: Kaitakusha.

Jackendoff, R. (1972). Semantic Interpretation in Generative Grammar. Cambridge, MA: MIT Press.

Kadmon, N. (2001). Formal Pragmatics: Semantics, Pragmatics, Presupposition and Focus. Oxford: Blackwell.

Kiaer, J. (2005). Incremental Parsing in Korean: At the Syntax-Phonology Interface. Master's Thesis, London: King's College.

Kitagawa, Y., \& Fodor, J. D. (2006). Prosodic Influence on Syntactic Judgments. In G. Fanslow, C. Féry, R. Vogel, \& M. Schlesewsky (Eds.), Gradience in Grammar (pp. 336-358). Oxford: Oxford University Press. http://dx.doi.org/10.1093/acprof:oso/9780199274796.003.0017

Kitagawa, Y., \& Kuroda, S. (1992). Passives in Japanese. Master's Thesis, San Diego, CA: University of Rochester and University of California.

Kobuchi, P. M. (2003). Distributivity and the Japanese Floating Quantifier. Ph.D. Thesis, New York: City University of New York.

Kobuchi, P. M. (2007). Floating Numerals and Floating Quantifiers. Lingua, 117, 814-831. http://dx.doi.org/10.1016/j.lingua.2006.03.008

Kubozono, H. (1993). The Organization of Japanese Prosody. Tokyo: Kuroshio Publishers.

Landman, F. (1989a). Groups I. Linguistics and Philosophy, 12, 559-605. http://dx.doi.org/10.1007/BF00627774

Landman, F. (1989b). Groups II. Linguistics and Philosophy, 12, 723-744. http://dx.doi.org/10.1007/BF00632603

Miyagawa, S., \& Arikawa, K. (2007). Locality in Syntax and Floating Numeral Quantifiers. Linguistic Inquiry, 38, 645-670. http://dx.doi.org/10.1162/ling.2007.38.4.645

Nakanishi, K. (2004). Domains of Measurement: Formal Properties of Non-split/Split Quantifier Constructions. Ph.D. Thesis, Philadelphia, PA: University of Pennsylvania.

Nakanishi, K. (2007). Formal Properties of Measurement Constructions. Berlin: Mouton de Gruyter.

Nakanishi, K. (2008). The Syntax and Semantics of Floating Numeral Quantifiers. In S. Miyagawa, \& M. Saito (Eds.), The Oxford Handbook of Japanese Linguistics (pp. 287-319). Oxford: Oxford University Press.

\footnotetext{
${ }^{12}$ Deguchi and Kitagawa (2002) offer arguments to show that the relationship between the typology of wh-questions and sentential stress has interesting implications for determining the type of a language with respect to wh-questions.
} 
Pierrehumbert, J., \& Beckman, M. E. (1988). Japanese Tone Structure. Cambridge, MA: MIT Press.

Poser, W. J. (1984). The Phonetics and Phonology of Tone and Intonation in Japanese. Ph.D. Thesis, Cambridge, MA: MIT. Steedman, M. (2000a). Information Structure and the Syntax-Phonology Interface. Linguistic Inquiry, 34, 649-689. http://dx.doi.org/10.1162/002438900554505

Steedman, M. (2000b). The Syntactic Process. Cambridge, MA: MIT Press.

Stirling, L. (1985). Distributives, Quantifiers and a Multiplicity of Events. In Proceedings of the 2nd Conference of the European Chapter of the Association of Computational Linguistics (pp. 16-24). Location: The Association for Computer Linguistics.

Takami, K. (1998). Nihongo no suuryoushiyuurinitsuite: kinourontekibunseki. Gekkan Gengo, 27, 86-107.

Yokota, K. (2013). On the Interpretation of Floating Numeral Quantifier Constructions in Japanese. Ph.D. Thesis, Osaka: Osaka Prefecture University. 
Scientific Research Publishing (SCIRP) is one of the largest Open Access journal publishers. It is currently publishing more than 200 open access, online, peer-reviewed journals covering a wide range of academic disciplines. SCIRP serves the worldwide academic communities and contributes to the progress and application of science with its publication.

Other selected journals from SCIRP are listed as below. Submit your manuscript to us via either submit@scirp.org or Online Submission Portal.
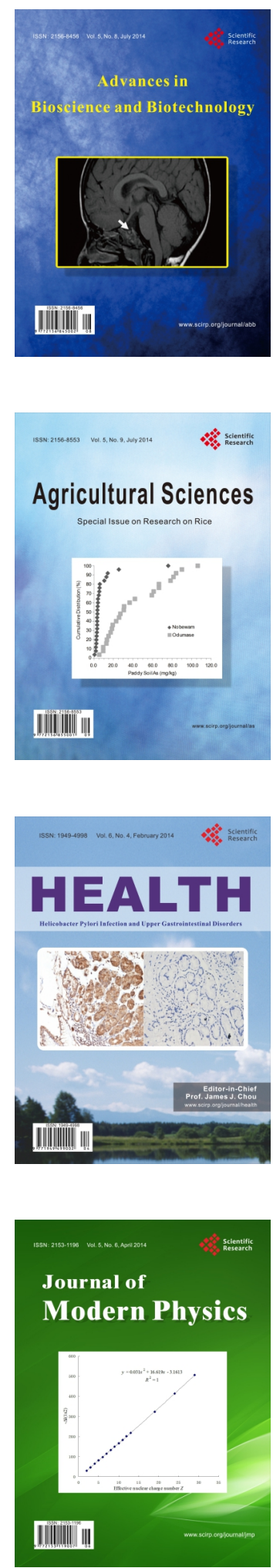
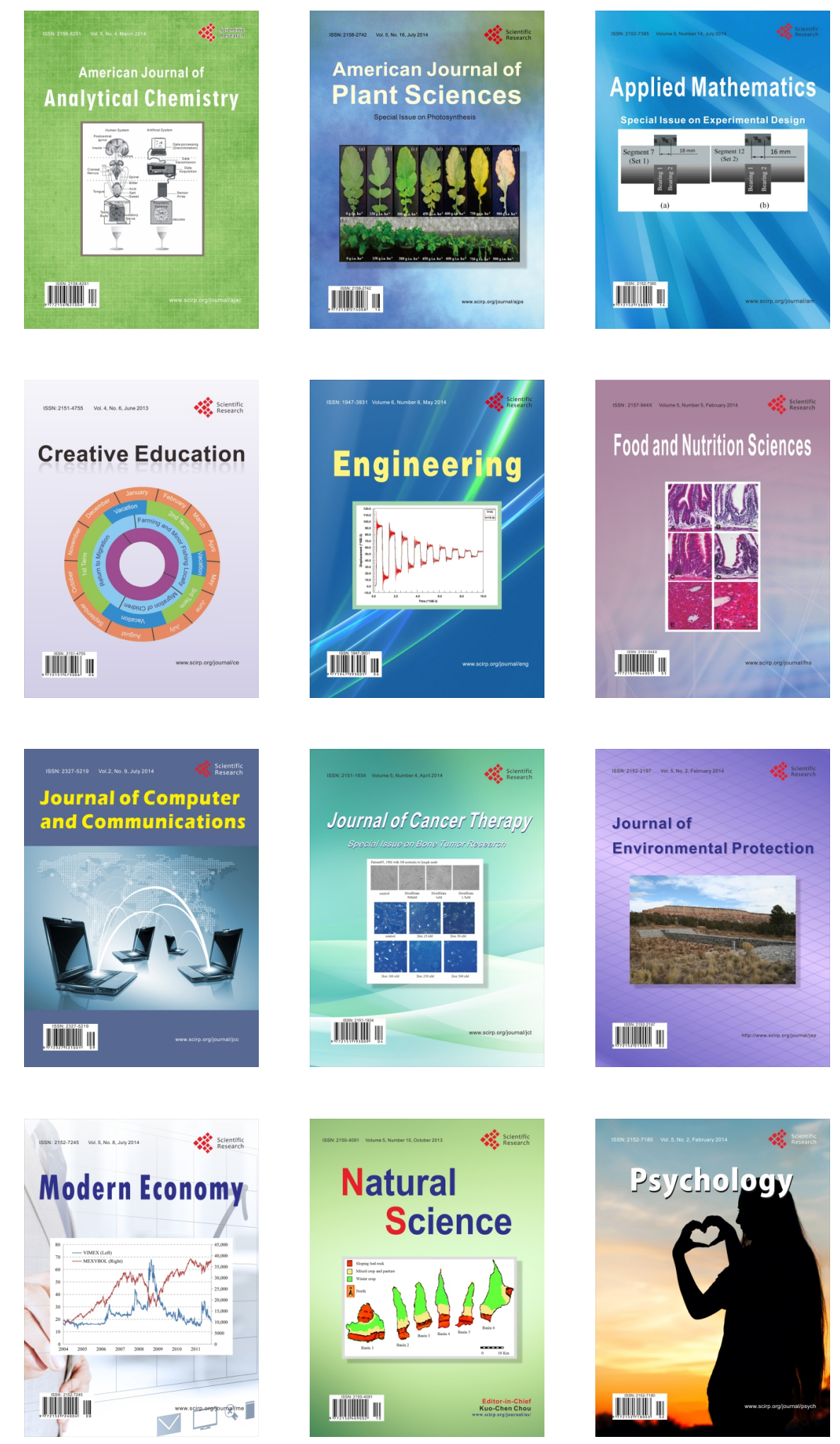